\title{
ACCURACY OF RANDHAWA AND PUJAHARI PREOPERATIVE SCORING SYSTEM IN PREDICTION OF DIFFICULT LAPAROSCOPIC CHOLECYSTECTOMY IN EGYPTIAN POPULATION
}

\author{
Ahmed Mohamed Kamal, Mohamed Mahmoud El-Said El-Matary, \\ Ehab Mohamed Ali Fadl and Nabil Sami Sadek Gebril**
}

\section{General Surgery Department, Faculty of Medicine, Ain Shams University, \\ *Police authority Hospital, Cairo, Egypt.}

Corresponding author Nabil Sami Sadek Gebril

Mobile: (+2) 01223604220

E.mail:

captainsurgeon3@gmail.com

Received: $13 / 1 / 2021$

Accepted: 3/2/2021

Online ISSN: 2735-3540

\begin{abstract}
Background: Laparoscopic cholecystectomy is the procedure of choice for management of symptomatic gallstone disease and one of the most commonly performed operations by general surgeons. Sometimes, it is difficult and takes longer time or has to be converted to an open procedure due to various difficulties faced while performing the procedure.
\end{abstract}

Aim of the Work: To evaluate the accuracy of Randhawa and Pujahari preoperative scoring system in prediction of difficult laparoscopic cholecystectomy in Egyptian population.

Patients and Methods: This is a prospective observational study that has been conducted in department of general surgery, Ain Shams University hospitals, including (60) patients undergoing elective laparoscopic cholecystectomy for symptomatic gall stones disease. The scoring system used was of Randhawa and Pujahari, based on history, clinical examination and radiological finding.

Results: Showed that the scoring system is reliable to be used in Egyptian patient with sensitivity $77.78 \%$ and specificity $95.12 \%$.

Conclusion: Ranhawa and Pujahari scoring system are reliable and could be used in Egyptian patients undergoing elective laparoscopic cholecystectomy. This scoring system can help each of patients, surgeons and trainers. With the help of accurate prediction, high risk patient may be informed before operation and hence they may have a chance to make arrangements accordingly. On the other hand, surgeons also may have to schedule the time and team for the operation appropriately.

Keywords: Laparoscopic cholecystectomy, Randhawa, Pujahari, Hepatobiliary Scintigraphy.

\section{INTRODUCTION}

Gall stone can affect any age group. As the age increases, the chances of gall stone disease increases. The prevalence of gall stone disease is around $25 \%$ in women aged above sixty years of age. Now a day, the gall stone disease is becoming more and more common $^{(\mathbf{1})}$. Symptoms are generally not seen in most of the cases of the gall stone disease. But it has been estimated that $10-20 \%$ of the cases will show symptoms after 5-20 years of development of the gall stones. Thus it is clear that the risk of becoming symptomatic in the case of gall stone disease is less and estimated at about 2-2.6\% per year ${ }^{(2)}$.

The use of laparoscopic cholecystectomy started in the year of 1987. It proved to be a boon to the patients it has many advantages compared to open cholecystectomy ${ }^{(3)}$. The patient has less hospital stay, less morbidity, 
better cosmoses laparoscopic cholecystectomy compared to open cholecystectomy. There are few or very minimum changes in the biochemical and physiologic responses. But the major disadvantages of the laparoscopic cholecystectomy are the increased chances of bile duct injury ${ }^{(4)}$.

To reduce the complications and conversion rate among the patients undergoing laparoscopic cholecystectomy, preoperative scores have been developed based upon the experience of surgeons. Certain pre-operative factors are thought to predict the difficult or extremely difficult laparoscopic cholecystectomy. Studies have shown the utility of the pre-operative scoring to predict the difficult or extremely difficult laparoscopic cholecystectomy ${ }^{(\mathbf{5})}$.

Hence present study was carried out to evaluate the accuracy of Randhawa and Pujahari of pre-operative scoring in predicting the difficult and extremely difficult laparoscopic cholecystectomy.

\section{AIM OF THE WORK}

To evaluate the accuracy of Randhawa and Pujahari preoperative scoring system in prediction of difficult laparoscopic cholecystectomy in Egyptian population.

\section{PATIENTS AND METHODS}

Prospective observational study has been conducted in department of general surgery, Ain Shams University hospitals, including (60) patients undergoing elective laparoscopic cholecystectomy for symptomatic gall stones disease from January 2020 to April 2020.

\section{Sample size:}

Sample size was calculated using Epicala software with the following inputs:
All patients will fulfill the following criteria:

- Type I error $(\alpha)=5 \%$ with confidence level $95 \%$.

- Study power $90 \%$ (power of test) with type II $10 \%$ (Beta).

- The significance level $(\alpha)$ at 0.05 .

Inclusion criteria for the recruited patients:

This study included sixty patients of both genders and of the age group older than 18 years undergoing elective laparoscopic cholecystectomy for symptomatic gall stones disease.

\section{Exclusion criteria for the recruited patients:}

- Patients admitted with current attack of acute cholecystitis.

- Laparoscopic to open conversion due to equipment failure.

- Patients with CBD stones.

- Laparoscopic cholecystectomy performed with other laparoscopic interventions in the same setting.

All the surgeries has been performed by an expert surgeon (Consultant) by conventional method using $\mathrm{CO} 2$ pneumoperitoneum, using standard two $5 \mathrm{~mm}$ and two $10 \mathrm{~mm}$ ports. Time has been noted from first the port site insertion till the last port closure.

Scoring system of Randhawa and Pujahari (table 1) has been given for each patient the day before the operation on the bases of history, clinical examination and radiological finding.

Laboratory parameters including ALP, AST, ALT, total and direct bilirubin were recorded to test whether they could be used to predict the difficulty of LC or not. 
Table (1): Scoring system of Randhawa and Pujahari:

\begin{tabular}{|c|c|c|c|}
\hline Scoring factors & Minimum & Maximum & Total \\
\hline $\begin{array}{l}\text { History: } \\
\text { - Age } \\
\text { - Gender } \\
\text { - History of hospitaliztion of } \\
\text { acute cholecystitis } \\
\end{array}$ & $\begin{array}{l}\text { - } \quad<50 \text { yrs }(0) \\
\text { - Female (1) } \\
\text { - No }(0)\end{array}$ & $\begin{array}{l}\text { - }>50 \text { yrs }(1) \\
\text { - Male (1) } \\
\text { - Yes (4) }\end{array}$ & $\begin{array}{l}1 \\
1 \\
4\end{array}$ \\
\hline $\begin{array}{l}\text { Clinical: } \\
\text { - BMI } \\
\text { - Abdominal scar } \\
\text { - Palpable Gall bladder }\end{array}$ & $\begin{array}{l}\text { - }<25(0) \\
\text { - } \mathrm{No}(0) \\
\text { - No }(0)\end{array}$ & $\begin{array}{l}\text { - } 25-27(1)>27.5(2) \\
\text { - Infra-umbilical (1) } \\
\text { - Supra umbilical (2) } \\
\text { - Yes (1) }\end{array}$ & $\begin{array}{l}2 \\
2 \\
1\end{array}$ \\
\hline $\begin{array}{l}\text { Sonography: } \\
\text { - Wall thickness } \\
\text { - Pericholecytic collection } \\
\text { - Impacted stone }\end{array}$ & $\begin{array}{l}\text { - } \text { Thin }(0) \\
\text { - No }(0) \\
\text { - No }(0)\end{array}$ & $\begin{array}{l}\text { - } \text { Thick >4mm (2) } \\
\text { - Yes (1) } \\
\text { - Yes (1) }\end{array}$ & $\begin{array}{l}2 \\
1 \\
1\end{array}$ \\
\hline
\end{tabular}

The patients were divided into categories of risks based on the total score:

0-5 $=$ No risk 6-10 $=$ Moderate risk 11-15 = High risk
All intra operative events like duration of surgery, bleeding, bile/stone spillage, injury to duct/artery has been recorded and surgery was labeled as easy/difficult/very difficult (table 2)

Table (2): Scale for categorization of patients operation difficulties:

\begin{tabular}{|l|c|c|c|}
\hline \multicolumn{1}{|c|}{ Parameters } & Easy & Difficult & Very difficult \\
\hline Time taken for surgery & $<60$ minutes & $60-120$ minutes & $>120$ minutes \\
\hline Bile/stone spillage & No & Yes & ---- \\
\hline Injury to duct or artery & No & Yes & --- \\
\hline Conversion to open & No & No & - \\
\hline
\end{tabular}

Analysis of data was done by IBM computer using SPSS (statistical program for social science version 21) as follows:

- Description of quantitative variables as mean, SD, \& Median.

- Description of qualitative variables as number and percentage.

- Chi-square test was used to compare qualitative variables between groups.

- Fisher exact test was used when one expected cell or more are less than 5 .

- Unpaired t-test was used to compare quantitative variables, in parametric data (SD<30\% mean).

- Mann Whitney test was used instead of unpaired t-test in non-parametric data (SD>30\% mean).

The scores were compared in each patient to come to a conclusion whether preoperative predictive score was a useful method or not.
All statistical analyses were performed with the program Statistical Package for the Social Science 12.0 (SPSS). A $p$ value of $\leq 0.05$ was accepted as statistically significant. Chi-square test/Fisher exact test was used to find the significant association of findings of preoperative score with intraoperative outcome. Area under ROC was used to find the diagnostic and predictive value of preoperative score for predicting the intraoperative outcome.

\section{RESULTS}

\section{Demographic data are as following:}

\section{A. According to gender:}

There were 9 males and 51 females. 
Table (3): Gender distribution in the study:

\begin{tabular}{|l|c|c|}
\hline & Number & $\%$ \\
\hline Male & 9 & 15 \\
\hline Female & 51 & 85 \\
\hline
\end{tabular}

\section{According to age and BMI:}

The age of the patients ranged between 19 and 73 years old with a mean of 39.2 \pm 12.1 . The population of the study has a BMI ranging between 22 and 49 with a mean of $30.9 \pm$ SD 5.9 .

Table (4): Age \& BMI distribution in the study:

\begin{tabular}{|c|c|c|c|c|}
\hline & Minimum & Maximum & Mean & SD \\
\hline Age & 19 & 73 & 39.2 & 12.1 \\
\hline BMI & 22 & 49 & 30.9 & 5.9 \\
\hline
\end{tabular}

Table (5): Mean score of easy and difficult operations:

\begin{tabular}{|l|c|c|c|}
\hline Operation & Easy & Difficult & P value \\
\hline Mean & $3 \pm 2$ & $7 \pm 2$ & $<0.001$ \\
Score & & & \\
+ SD & & & \\
\hline
\end{tabular}

Table (15): Analysis of gender difference in relation to difficulty of the operation:

\begin{tabular}{|l|c|c|c|}
\hline Operation & Easy & Difficult & $\begin{array}{c}\text { P } \\
\text { value }\end{array}$ \\
\hline Male & 6 & 3 & 0.144 \\
\hline Female & 46 & 5 & \\
\hline
\end{tabular}

Male gender is not statistically significant risk factor for difficult LC with $\mathrm{P}$ value 0.144 .

Table (6): Analysis of history of hospitalization due to acute attack in relation to difficulty of the operation

\begin{tabular}{|l|c|c|c|}
\hline $\begin{array}{c}\text { History of } \\
\text { hospitalization }\end{array}$ & Easy & Difficult & $\begin{array}{c}\text { P } \\
\text { value }\end{array}$ \\
\cline { 1 - 3 } Yes & 3 & 7 & $<0.001$ \\
\cline { 1 - 3 } No & 49 & 1 & \\
\hline
\end{tabular}

\section{DISCUSSION:}

Laparoscopic cholecystectomy (LC) has become the procedure of choice for management of symptomatic gall stone disease. It has been observed that surgeons encountered difficulty during LC when there were dense adhesions at calot's triangle, fibrotic and contracted gallbladder, acutely inflamed or gangrenous gall bladder and cholcystoenteric fistula etc. There are many risk factors which make laparoscopic surgery difficult like old age, male sex, attacks of acute cholecystitis with fever and leucocytosis, obesity, previous abdominal surgery, clinical signs of acute cholecystitis, and certain ultrasonographic findings i.e. thickened gall bladder wall, distended gall bladder, pericholecystic fluid collection, impacted stone etc.

Several studies had been carried out to assess the risk of conversion preoperatively. In a study conducted by Kama et al. ${ }^{(6)}$ six parameters namely male sex, upper abdominal tenderness at the time of surgery, previous upper abdominal surgery, sonographically ascertained thick gallbladder wall, age $>60$ years and preoperative diagnosis of acute cholecystitis were found to have significant effect on risk of conversion on multivariate analysis. According to another similar study by Lee et $a \boldsymbol{a l} .{ }^{(7)}$ the risk factors for conversion included age > 65 yrs, male sex, patients with previous upper abdominal surgery and a documented history of acute cholecystitis.

In this study, the mean age of the population was 39.2 years and SD \pm 12.1 ranging from 19 to 73 years old. We find that that age was not significant risk factor for difficult LC with P value 0.385.

Randhawa et al study included 228 patients with the age ranging from 9 to 71 years old with mean age 44.37 years (SD \pm 12.45 ) Maximum cases were in the age group of $30-50$ years $(54.4 \%)$. They found that that age is not significant predictor for difficult $L C$ with $P$ value $=0.937^{(8)}$.

In 2017, Khetan and Yeola found in their study that the majority of patients were in the age group of $\leq 50$ years ( 25 patients) and only $16.7 \%$ (five cases) were $>50$ years. They found no significant correlation between age and the difficult level of surgery. This could be explained by the small sample size of the study population (30 cases) ${ }^{(\mathbf{9})}$. 
On the other hand, in a meta-analysis by Yang et al. demonstrated that age $>65$ years is associated with a twofold increase in conversion rate from LC to open surgery ${ }^{(\mathbf{1 0})}$.

These findings can be explained by a higher proportion of severe AC, choledocholithiasis and previous abdominal operations among the older patients compared to their younger counterparts ${ }^{(11)}$.

The present study shows that male gender is not statistically significant risk factor for difficult $\mathrm{LC}$ with $\mathrm{P}$ value 0.144. Randhawa et al study showed the same sex results with $\mathrm{P}$ value $0.144^{(8)}$.

Sippy et al study in 2015 found that males have more prominent adhesions between the GB and the momentum and surrounding internal organs, have a higher conversion rate and require a longer operation time ${ }^{(\mathbf{1 2})}$.

The population of the present study has a BMI ranging between 22 and 49 with a mean of $30.9 \pm 5.9$. Only $55.6 \%$ of difficult cases were with BMI more than $27.5 \mathrm{~kg} / \mathrm{m}^{2}$. $\mathrm{BMI}$ is not statistically significant risk factor for $\mathrm{LC}$ with $\mathrm{P}$ value 0.442 . Randhawa et al study showed similar BMI results with $\mathrm{P}$ value $0.227^{(\boldsymbol{8})}$.

Goonawardena et al study showed that obese patients undergoing LC have an eightfold higher risk of convertion to open CTO than non-obese patients ${ }^{(\mathbf{1 3})}$. Compared to the non-obese patients, class I and class II-III obese patients have a two- and threefold increase in the risk of CTO respectively ${ }^{(\mathbf{1 4})}$.

The present study shows seven of the eight difficult cases gave history of hospitalization due to acute attack of cholecystitis with or without obstructive jaundice, ERCP or biliary pancreatitis .We found that history of hospitalization for acute attack is statistically significant risk factor for difficult LC with P value $<0.001$.
Randhawa et al study showed that 14 cases of 18 difficult cases gave history of hospitalization and found hospitalization parameter is statistically significant risk factor for difficult $\mathrm{LC}$ with $\mathrm{P}$ value $<0.001^{(8)}$.

In 2017, Khetan et al study found that previous history of hospitalization for acute attack of cholecystitis is statistically significant risk factor for difficult LC ${ }^{(9)}$.

Boerma et al. compared the two stage LC conducted for patients with residual gall stones within 6 weeks from ERCP with that performed 6 weeks after ERCP and found that, the latter was more technically demanding and associated with a threefold increase in the CTO rate ${ }^{(\mathbf{1 5})}$. In 2015, Argwal et al study found that previous history of hospitalization is statistically significant predictor for difficult $\mathrm{LC}$ with $\mathrm{P}$ value $0.004^{(\mathbf{1 6})}$.

Another study performed in 2016 by Beliaev et al found that a two-stage LC after 15 weeks following ERCP/ES increases the rate of conversion to three times ${ }^{(17)}$. In 2011, Reinders et al study found that difficulty of LC after ERCP cound be explained by bactibilia-related inflammation of bile ducts with desmoplastic changes around the Calot's triangle and shrinking of the $\mathrm{GB}^{(\mathbf{1 8})}$.

The present study finds that GB wall thickening in ultrasound is statistically significant risk factor for difficult LC, $88.9 \%$ of difficult cases had GB wall thickening in preoperative abdominal ultrasound with $\mathrm{P}$ value $(0.007)$.

In 2017, Khetan et al study found that increased GB wall thickness is statistically significant predictor for difficult $\mathrm{LC}^{(\mathbf{9})}$. In 2007, Lipman et al study found that thickened gallbladder wall on ultrasound (US) is associated with high rate of CTO ${ }^{(\mathbf{1 9})}$.

Another study performed in 2015 by Goonawardena et al showed that the risk of conversion to open surgery doubles with 
every millimeter increase in gallbladder wall thickness. Patients with GB wall thickness $>5 \mathrm{~mm}$ on transabdominal US have a 16 times higher risk of CTO than those with GB wall thickness 3-5 $\mathrm{mm}^{(\mathbf{1 3})}$.

In 2017, Siddiqui et al study found that GB wall thickness of more than $4 \mathrm{~mm}$ was significantly associated with difficulty during LC. In gallstone disease, the most common reason for wall thickening is acute or chronic pericholecystic inflammatory change. An acutely inflamed and edematous GB wall may rupture with spillage of infected bile and stones can further limit visualization of the operative field, resulting in a more difficult operation ${ }^{(\mathbf{2 0})}$.

The present study shows that pericholecystic collection on preoperative ultrasound is statistically significant risk for difficult LC with P value 0.029.

In 2015, study performed by Nidoni et al found that the presence of pericholecystic fluid on imaging of the abdomen increases the risk of CTO by 26 times. This radiological sign has the sensitivity of $70 \%$ in predicting CTO, the specificity of $92 \%$, the positive predictive value of $33 \%$ and the negative predictive value of $98 \%{ }^{(21)}$.

In 2017, Siddiqui et al study found that there was no any statistical significance between difficulty during LC and the presence of pericholecystic collection, multiple stones or enlarged liver ${ }^{(\mathbf{2 0})}$.

The present study shows that previous lower abdominal surgery is not statistically significant risk factor for difficult LC with $\mathrm{P}$ value 0.414 . The present study didn't score any case with palpable GB or with previous history of upper abdominal surgery.

Randhawa et al study found that previous upper and lower abdominal surgery is insignificant predictor for difficult LC ( $p$ 0.882 ), it could be explained by increasing experience on adhesiolysis and advanced laparoscopic surgery, conversion is less often seen $^{(8)}$.
In 2012 Paajanen et al study found that the risk for CTO for patients with the past history of upper abdominal surgery 20 times higher than for those without previous surgery above the umbilicus ${ }^{(\mathbf{1 4})}$.

In 2015, Agrawal et al study found that previous upper abdominal surgery is statistically significant risk factor for difficult LC with $\mathrm{P}$ value $0.009^{(\mathbf{1 6})}$. The present study scored only one case with impacted stone and it was difficult. Randhawa et al study found that impacted stone is not statistically significant risk factor for difficult $\mathrm{LC}^{(\mathbf{8})}$.

In 2017, Siddiqui et al study found that patients with an impacted stone had higher incidence of operative difficulty and the association between the two was statistically significant ${ }^{(20)}$.

The present study shows that at score $\leq$ 5 , it has sensitivity $77.78 \%$ and specificity $95.12 \%$ with positive predictive value 77.8 $\%$ and negative predictive value $95.1 \%$. Similar to the results of the original study by Randhawa and Pujahar that was showing sensitivity $75.00 \%$ and specificity $90.24 \%$ at score $\leq 5^{(8)}$. In 2015, Agrawal et al study found that the proposed scoring system is reliable with a sensitivity of $76.47 \%$ and specificity of $100 \%{ }^{(\mathbf{1 6})}$.

In 2017, Khetan et al study found that the scoring system had a positive prediction value for easy prediction of $81.9 \%$ and for difficult prediction of $75 \%$ (9). In the present study prediction came true in $95 \%$ of easy cases and $77.8 \%$ of difficult cases, and there were no cases with score above 10 .

In Argwal et al study prediction came true in $76.4 \%$ for easy and $100 \%$ difficult cases; there were no cases with a score above $10^{(\mathbf{1 6})}$. The present study scores ALP before the operation and it finds that elevated ALP is statistically significant factor for difficult LC with P value 0.008, but it shows that Elevated ALT\&AST are 
not statistically significant risk factors for difficult LC.

\section{Conclusion:}

This study shows that Ranhawa and Pujahari scoring system are reliable and could be used in Egyptian patients undergoing elective laparoscopic cholecystectomy. This scoring system can help each of patients, surgeons and trainers. With the help of accurate prediction, high risk patient may be informed before operation and hence they may have a chance to make arrangements accordingly. On the other hand, surgeons also may have to schedule the time and team for the operation appropriately.

Surgeons can also be aware about the possible complications that may arise in high risk patients. It could be involved in training process for residents and junior staff. It helps also in prediction of high possibility for conversion from LC to open surgery. It can be useful if senior staff use this scoring system to arrange cases on OR list with anesthesia team and to select cases suitable for training of juniors.

\section{REFERENCES}

1. Vakili K, Pomfret EA (2008): Biliary anatomy and embryology. Surgical Clinics of North America; 88(6):1159-74.

2. Friedman GD, Raviola CA, Fireman B (2009): Prognosis of gallstones with mild or no symptoms: 25 years of follow-up in a health maintenance organization. J Clin Epidemiol; 42 (2):127-136.

3. Paajanen H, Suuronen S, Nordstrom P, Miettinen P, Niskanen L (2011): Laparoscopic versus open cholecystectomy in diabetic patients and postoperative outcome. Surgical endoscopy; 25(3):76470.

4. Mohanty SK (2017): Pre-Operative Prediction of Difficult Laparoscopic Cholecystectomy Using Clinical and Ultrasonographic Parameters. Ann. Int. Med. Den. Res; 3(4):43-48.
5. Sudhir M, Raj P (2018): Preoperative Grading System versus Intraoperative Grading System as Predictors for Difficult Laparoscopic Cholecystectomy: A Comparative Validation Study. J Clin Basic Res.; 2(1):39-47.

6. Kama NA, Kologlu M, Doganay M, Reis E, Atli $\mathrm{M}$ and Dolapci M (2001): A risk score for conversion from laparoscopic to open cholecystectomy. The American Journal of Surgery; 181(6): 520-525.

7. Lee NW, Collins J, Britt R, Britt LD (2012): Evaluation of preoperative risk factors for converting laparoscopic to open cholecystectomy. Am Surg; 78(8):8313.

8. Randhawa JS and Pujahari AK (2009): Preoperative prediction of difficult lap chole: a scoring method. Indian Journal of Surgery; 71(4): 198-201.

9. Khetan AK, Yeola M (2017): Preoperative prediction of difficult laparoscopic cholecystectomy using a scoring system. International Surgery Journal; 4(10):338891.

10. Yang TF, Guo L, Wang Q (2014): Evaluation of Preoperative Risk Factor for Converting Laparoscopic to Open Cholecystectomy: A Meta-Analysis. Hepato-gastroenterology; 61(132):958-65.

11. Licciardello A, Arena M, Nicosia A, Di Stefano B, Cali G, Arena G, Minutolo V (2014): Preoperative risk factors for conversion from laparoscopic to open cholecystectomy. Eur Rev Med Pharmacol Sci.; 18(2 Suppl):60-8.

12. Sippy M, Grzybowski M, Manwaring ML, Kasten KR, Chapman WH, Pofahl WE, Pories WJ, Spaniolas K (2015): Acute cholecystitis: risk factors for conversion to an open procedure. Journal of surgical research; 199(2):357-61.

13. Goonawardena J, Gunnarsson R, de Costa A (2015): Predicting conversion from laparoscopic to open cholecystectomy presented as a probability nomogram based on preoperative patient risk factors. Am J Surg; (3):492-500.

14. Paajanen H, Kakela $P$, Suuronen S, Paajanen J, Juvonen P, Pihlajamaki J (2012): Impact of obesity and associated 
diseases on outcome after laparoscopic cholecystectomy. Surg Laparosc Endosc Percutan Tech; 22(6):509-13.

15. Boerma D, Rauws EA, Keulemans YC, Janssen IM, Bolwerk CJ, Timmer R, Boerma EJ, Obertop H, Huibregtse K, Gouma DJ (2002): Wait-and-see policy or laparoscopic cholecystectomy after endoscopic sphincterotomy for bile-duct stones: a randomised trial. The Lancet; 360(9335):761-5.

16. Agrawal P, Gupta K, Mishra V, Agrawal S (2015): The psychosocial factors related to obesity: a study among overweight, obese, and morbidly obese women in India. Women \& health; 55(6):623-45.

17. Beliaev AM, Marshall RJ, Booth M (2016): C-reactive protein has a better discriminative power than white cell count in the diagnosis of acute cholecystitis. J Surg Res; 198(1): 66-72.

18. Reinders JS, Kortram K, Vlaminckx B, van Ramshorst B, Gouma DJ and Boerma D
(2011): Incidence of bactobilia increases over time after endoscopic sphincterotomy. Dig Surg. [Multicenter Study Randomized Controlled Trial]; 28(4):288-92.

19. Lipman JM, Claridge JA, Haridas M, Martin MD, Yao DC, Grimes KL, Malangoni MA (2007): Preoperative findings predict conversion from laparoscopic to open cholecystectomy. Surgery; 142(4):556-65.

20. Siddiqui MA, Rizvi SA, Sartaj S, Ahmad I and Rizvi SW (2017): A standardized ultrasound scoring system for preoperative prediction of difficult laparoscopic cholecystectomy. Journal of medical ultrasound; 25(4): 227-231.

21. Nidoni R, Udachan TV, Sasnur P, Baloorkar R, Sindgikar V, Narasangi B (2015): Predicting difficult laparoscopic cholecystectomy based on clinicoradiological assessment. J Clin Diagn Res; 9(12): PC09-12. 
تقييم دقة نظام رانداهاوا وبوجاهري في التتبؤ بصعوبة عملية استئصال المرارة بالمنظار الجراحي

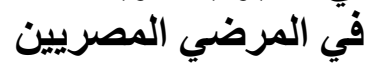

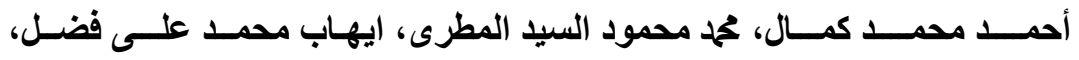
نبيل سامى صادق

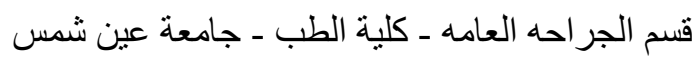

مستشفى هيئة الشرطة

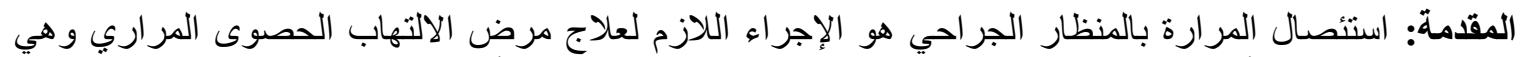

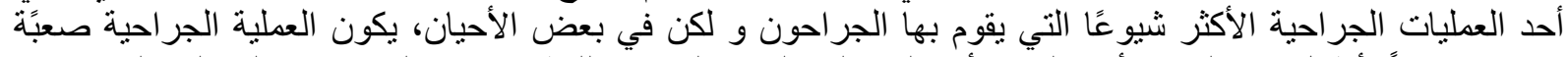

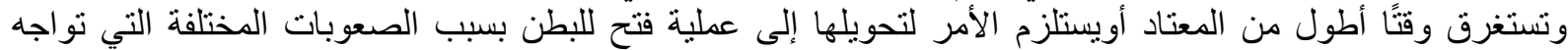
الجر اح أثناء اجر اء العميلة.

الهُف من البحث: هو تقييم دقة نظام رانداهاوا و بوجاهري في التنبؤ بصعوبة عملية استئصال المرارة بالمنظار الجر احي في المرضي المصن هوبين.

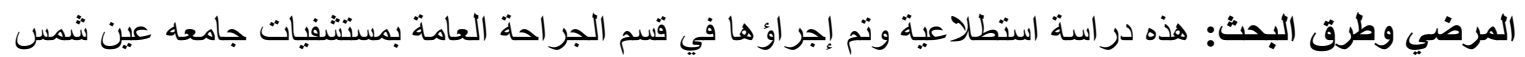

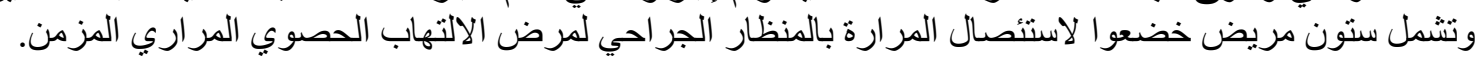

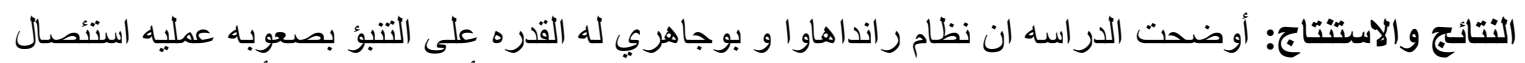

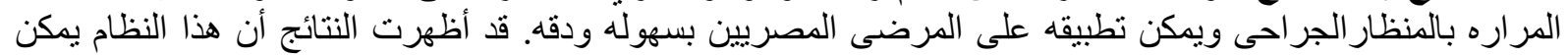

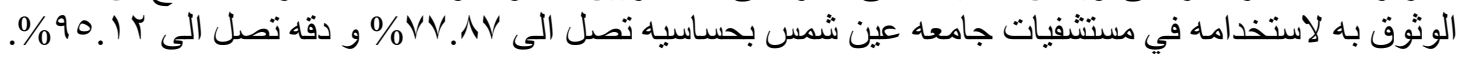

